\title{
FLORESTAS PLANTADAS DE EUCALIPTO NO BRASIL: UMA CULTURA NOCIVA AOS RECURSOS HÍDRICOS?
}

\author{
Beatriz Souza Costa ${ }^{1}$ \\ Escola Superior Dom Helder Câmara (ESDHC) \\ Márcio Luís Oliveira² \\ Escola Superior Dom Helder Câmara (ESDHC)
}

\section{RESUMO}

O objeto deste trabalho relaciona-se à investigação do plantio de eucalipto e seus eventuais efeitos nocivos aos recursos hídricos, em observância aos princípios da precaução e da prevenção. Assim, como hipóteses, o artigo propõe-se a aferir a veracidade ou não da nocividade do eucalipto para os recursos hídricos, de modo que seja recomendada a substituição ou a continuidade da atividade econômica de plantio do eucalipto por meio da adoção de políticas públicas específicas para o setor. A metodologia utilizada na pesquisa foi dedutiva, tendo sido utilizados os métodos qualitativo de dados, descritivo, comparativo e analítico. Como fontes primárias, a pesquisa pautou-se pela consulta bibliográfica a livros e artigos disponibilizados em revistas científicas.

Palavras-chave: cultivo do eucalipto; florestas plantadas; princípios da precaução e da prevenção no Direito Ambiental; recursos hídricos.

\footnotetext{
1 Pós-doutora em Direito pela Universidad Castilla-La Mancha (UCLM). Doutora e mestre em Direito Constitucional pela Universidade Federal de Minas Gerais (UFMG). Pró-Reitora de Pesquisa e Professora do mestrado e doutorado em Direito Ambiental e Desenvolvimento Sustentável da ESDHC. ORCID: https://orcid.org/0000-0003-0636-6081 / e-mail: biaambiental@yahoo.com.br.

2 Doutor e mestre em Direito pela UFMG. Aperfeiçoamento em Direito Internacional Público e Privado (Países Baixos). Professor da Faculdade de Direito da UFMG, do mestrado e doutorado na ESDHC e do mestrado na Faculdade Milton Campos. Professor-visitante na Universidad Complutense de Madrid (UCM). Professor-colaborador na The Hague University of Applied Sciences. Consultor-geral da Consultoria Técnico-Legislativa do Governo de Minas Gerais. ORCID: https://orcid.org/00000001-7437-0766 / e-mail: marcio.luis@uol.com.br.
} 


\section{PLANTED FORESTS WITH EUCALYPTUS IN BRAZIL: A HARMFUL CULTURE TO WATER RESOURCES?}

\section{ABSTRACT}

The object of this study is related to the investigation of eucalyptus plantations and their possible harmful effects on water resources, in compliance with the principles of precaution and prevention. Thus, as hypotheses, the article proposes to assess the veracity or not of the harmfulness of eucalyptus to water resources, so that it is recommended the replacement or continuity of the economic activity of eucalyptus planting by the adoption of specific public policies for the sector. The methodology used in the research was deductive, also qualitative, descriptive, comparative and analytical methods were used. As primary sources, the research was guided by the bibliographic consultation of books and articles available in scientific journals.

Keywords: eucalyptus cultivation; planted forests; principles of precaution and prevention in Environmental Law; water resources. 


\section{INTRODUÇÃO}

As plantações de eucaliptos foram introduzidas no Brasil no século XIX, sendo esta espécie nativa da Oceania e principalmente da Austrália. A partir da década de 1960, houve a expansão da cultura do eucalipto e do pinus com diversas finalidades comerciais e industriais - inclusive como fonte energética especialmente para a siderurgia -, cuja demanda é crescente pelos mercados nacional e internacional desde então. Por se tratar de florestas plantadas, o objetivo das árvores é serem cortadas ou colhidas, e os empresários do setor rejeitam a designação de reflorestadores que lhes é comumente atribuída.

As florestas plantadas de eucalipto têm diversos usos, destacando-se como fonte de energia para forjar o ferro gusa e o ferro liga, e para a produção de móveis, painéis de madeira, madeira processada, celulose e papel.

Contudo, o setor é comumente considerado nocivo para os recursos hídricos e para a biodiversidade. De maneira geral, existe a crença de que a plantação de eucalipto, em seu desenvolvimento, além de ser uma floresta sem frutos, seca nascentes e prejudica a vazão de rios próximos. Portanto, a problematização deste artigo tem como tema-problema: o plantio de eucalipto é nocivo à disponibilização e ao uso dos recursos hídricos, de modo a se exigir do Estado e do setor produtor a observância do princípio da precaução?

Logo, o marco téorico do artigo é o princípio da precaução no Direito Ambiental e sua aplicabilidade à monocultura de eucalipto no Brasil. Assim, como hipóteses, o artigo se propõe a aferir a veracidade ou não da nocividade do eucalipto para os recursos hídricos, de modo que seja recomendada a substituição ou a continuidade da atividade econômica de plantio do eucalipto pela adoção de políticas públicas específicas para o setor.

Nesse sentido, o artigo tem por objeto geral analisar a cultura do eucalipto como atividade econômica sustentável na modalidade de floresta plantada no Brasil. Como objeto específico, o artigo busca investigar os eventuais impactos dessa cultura sobre os recursos hídricos, em observância ao princípio da precaução e, subsidiariamente, ao princípio da prevenção.

A metodologia utilizada na pesquisa foi dedutiva, e foram utilizados os métodos: qualitativo de dados, descritivo, comparativo e analítico. Como fontes primárias, a pesquisa pautou-se pela consulta bibliográfica a livros e 
artigos disponibilizados em revistas científicas, inclusive via internet.

Em síntese, o artigo, além da introdução, das conclusões finais e das referências bibliográficas, foi organizado em três tópicos. No primeiro, houve o relato das origens, dos ciclos e da expansão do plantio do eucalipto no território brasileiro. No segundo item, o artigo tratou do tema das florestas plantadas no Brasil e abordou, de modo exemplificativo, esse tipo de cultura em outros países com a finalidade de situar o Brasil no mercado global por demanda de madeira, além da utilização desse plantio como meio de preservação das florestas nativas. O terceiro ponto foi dedicado ao objeto central do artigo, os impactos da cultura de eucalipto na disponibilidade e uso dos recursos hídricos e as demais repercussões ambientais e socioeconômicas da atividade.

\section{CICLOS DE DESENVOLVIMENTO DO EUCALIPTO NO BRASIL}

A Organização das Nações Unidas para Agricultura e Alimentação define floresta como "Land spanning more than 0.5 hectares with trees higher than 5 meters and a canopy cover of more than 10 percent, or trees able to reach these thresholds in situ. It does not include land that is predominantly under agricultural or urban land use"3 (FAO, 2015a). Considerando essa definição, o Brasil tem cerca de 59\% de seu território coberto por florestas naturais e plantadas, o que representa a segunda maior área florestal do mundo, precedida apenas da Rússia; desse percentual, cerca de 500 milhões de hectares são de florestas nativas e 10 milhões de hectares de florestas plantadas (SNIF, 2018).

Entre as florestas plantadas, e para fins deste artigo, destacam-se as de eucalipto, espalhadas pelo território nacional. Porém, o eucalipto não faz parte da flora primitiva brasileira, sendo uma planta exótica proveniente da Austrália, Tasmânia e outras ilhas da Oceania, que conta com mais de 730 espécies reconhecidas pela Botânica (EMBRAPA, 2019). Contudo, apenas 20 das espécies de eucalipto são atualmente utilizadas para fins comerciais em todo o mundo (SANTAROSA; PENTEADO JÚNIOR; GOULART, 2014).

Tem-se notícia da primeira plantação de eucalipto no Brasil, na cidade do Rio de Janeiro, em 1825 (CARVALHO; SILVA, 1992, p. 42). Assim, iniciaram-se os ciclos da floresta plantada com o eucalyptus grandis e o

3 Tradução livre: "Terreno acima de 0,5 hectares de árvores com mais de 5 metros de altura (ou com capacidade para atingirem tal altitude) e com área superior a $10 \%$ coberta por copa de árvores. Na definição, não se incluem as terras predominantemente sob uso agrícola ou urbano". 
eucalyptus tereticornis. O segundo ciclo da floresta plantada ocorreu na década de 1970, e o terceiro, por sua vez, nos anos de 1980, quando se deu início a melhoramentos genéticos com o desenvolvimento da biotecnologia. $\mathrm{O}$ quarto ciclo da floresta seguiu-se com mais avanços genéticos e com a criação de novas espécies para utilização na indústria moveleira. Outros ciclos seguiram-se, com alterações genéticas, inclusive com foco na pauta ambiental e sob novos marcos da legislação (CARVALHO; SILVA, 1992, p. 42-43).

Comercialmente, o setor de florestas plantadas deu um salto na década de 2000 e anos seguintes. A Indústria Brasileira de Árvores (IBÁ) elaborou um sumário estatístico demonstrando que em 2017, os investimentos na área chegaram a $\mathrm{R} \$ 6,7$ bilhões, sendo $\mathrm{R} \$ 3,2$ bilhões nas florestas e $\mathrm{R} \$$ 3,5 bilhões na indústria (IBÁ, 2017). Contudo, exclusivamente na área total de árvores plantadas, o Brasil alcançou 7,84 milhões de hectares em 2017 (IBÁ, 2017). Com isso, a participação do setor de eucalipto somou R \$ 73,8 bilhões naquele ano, representando cerca de $1,1 \%$ do Produto Interno Bruto (PIB) nacional e 6,1\% do industrial (IBÁ, 2017). No mesmo período, o Brasil bateu recorde na produção de celulose, chegando a 19,5 milhões de toneladas do produto, e passando ao segundo lugar mundial, tendo ultrapassado o Canadá e a China (IBÁ, 2017). Ademais, o Brasil está entre os 10 países produtores de papel (10,5 milhões de toneladas), painéis de madeira (7,9 milhões de $\left.\mathrm{m}^{3}\right)$, piso (11,9 milhões de $\left.\mathrm{m}^{3}\right)$ e carvão vegetal (4,5 milhões de toneladas) (IBÁ, 2017).

Atualmente, o Brasil detém tecnologia avançada no melhoramento genético de eucaliptos. Até mesmo a Austrália busca no Brasil as espécies melhoradas para seu plantio (IBÁ, 2017). Constata-se que o setor de base florestal é capilarizado, de modo que existem várias atividades que dependem dele para sobreviver. Trata-se de um importante insumo, cuja demanda tem crescido em todo o mundo em razão de sua relevância socioeconômia. Por isso, é necessário que a expansão da cultura de eucalipto seja sustentável, uma vez que a produção comercial de madeira deve resultar das florestas plantadas para que as florestas naturais não sofram com a pressão do consumo.

\section{O COMPLEXO DE FLORESTAS PLANTADAS NO BRASIL}

As florestas plantadas para fins econômicos têm crescido no Brasil, merecendo, por conseguinte, atenção dos seterores de proteção ambiental. 
No complexo de florestas plantadas, o eucalipto e o pinus têm notórios destacaques. De acordo com o Sistema Nacional de Informação Florestal (SNIF), as florestas plantadas representam milhões de hectares, a saber:

Tabela 1 Florestas plantadas em território brasileiro em hectares por espécie entre 2014 e 2017.

\begin{tabular}{|l|l|l|l|l|}
\hline Espécie florestal & \multicolumn{1}{|c|}{$\mathbf{2 0 1 4}$} & \multicolumn{1}{|c|}{$\mathbf{2 0 1 5}$} & \multicolumn{1}{|c|}{$\mathbf{2 0 1 6}$} & \multicolumn{1}{|c|}{$\mathbf{2 0 1 7}$} \\
\hline Eucalipto & 6.952 .509 & 7.444 .625 & 7.543 .707 & 7.411 .276 \\
\hline Pinus & 2.049 .234 & 2.065 .560 & 2.079 .162 & 2.030 .419 \\
\hline Outras & 364.998 & 427.762 & 400.207 & 410.025 \\
\hline Total & 9.368 .755 & 9.939 .962 & 10.025 .092 & 9.853 .737 \\
\hline
\end{tabular}

Fonte: SNIF (2018).

Nota-se, na Tabela 1, o crescimento exponencial da floresta de eucalipto nos anos de 2014, 2015 e 2016, com pequena queda em 2017. Os dados utilizados pelo SNIF são provenientes do Instituto Brasileiro de Geografia e Estatística (IBGE). Percebe-se uma grande diferença entre as culturas de eucalipto e de pinus, se comparadas a outras espécies florestais plantadas no Brasil. O eucalipto, mais do que o pinus, tem uma maior utilização na indústria.

A título de informação, em Minas Gerais, maior produtor de eucalipto do Brasil, o plantio ocorre com maior frequência nas regiões do Rio Doce, Centro-Oeste, Noroeste, Centro-Norte, Jequitinhonha e Mucuri (BORGES; LEITE; LEITE, 2018). Em 2016, Minas Gerais chegou a 1.955.578 milhões de hectares de áreas plantadas (SNIF, 2018).

Apesar de ter havido a expansão de florestas plantadas no Brasil, com a predominância do eucalipto, e de o país apresentar clima favorável para a produção de madeira comercial, o Brasil ainda se posiciona timidamente no mercado internacional, como se pode aferir pelo ranking mundial em milhões de hectares plantados, fornecidos pelo Global Forest Resources Assessment:

Tabela 2 Distribuição de florestas plantadas em milhões de hectares por país.

\begin{tabular}{|l|l|}
\hline \multicolumn{1}{|c|}{ País } & Milhões por ha \\
\hline China & 78.982 .000 \\
\hline Rússia & 19.841 .000 \\
\hline Canadá & 15.784 .000 \\
\hline Suécia & 13.737 .000 \\
\hline Índia & 12.031 .000 \\
\hline
\end{tabular}




\begin{tabular}{|l|l|}
\hline Japão & 10.270 .000 \\
\hline Polônia & 8.957 .000 \\
\hline Brasil & 7.736 .000 \\
\hline Finlândia & 6.775 .000 \\
\hline
\end{tabular}

Fonte: FAO (2015b).

Como se pôde observar, o Brasil tem uma baixa participação no crescente mercado internacional, e deve enfrentar vários desafios para aumentar sua produção, entre eles, o de eliminar mitos que ainda se mantêm nesse tipo de empreendimento.

Havendo estímulos na produção, o Brasil ultrapassaria países como a China, Rússia e Canadá, pois no Brasil o tempo de colheita das principais espécies plantadas é de 5 a 7 anos, ao passo que nos países mencionados esse tempo é maior por causa das baixas temperaturas. Logo, os produtores brasileiros têm perdido oportunidades frente a um mercado altamente promissor, tendo o Brasil condições básicas para aumentar sua participação no comércio internacional.

Como visto, o Brasil detém a oitava posição no ranking de produção mundial de florestas plantadas e é o maior produtor de celulose segundo o Sistema Nacional de Informação Florestal (SNIF, 2018). O SNIF prevê que, em 2050, a população do planeta alcançará 9,1 bilhões de pessoas, e a demanda por bioenergia será crescente, portanto, haverá necessidade de plantio de mais de 250 milhões de hectares de florestas para suprir a procura por esta comodite.

Embora a discussão econômica seja importante, haja vista a promoção da inclusão socioeconômica, além da geração de riquezas, e este trabalho tem como foco a verificação dos impactos negativos da plantação de eucalipto sobre os recursos hídricos.

Assim, no tópico seguinte, será verificada a correlação entre a expansão da cultura do eucalipto e os possíveis impactos ambientais dessa produção, especialmente quanto à disponibilidade e ao uso dos recursos hídricos.

\section{OS IMPACTOS CAUSADOS PELA PLANTAÇÃO DE EUCALIPTO NO MEIO AMBIENTE: PARTICURLAMENTE NOS RECURSOS HÍDRICOS}

É difícil afirmar que uma planta exótica como o eucalipto não interfira de modo prejudicial no meio ambiente principalmente quando 
se tem, no Brasil, um montante próximo de 10 milhões de hectares da espécie em florestas plantadas (SNIF, 2018). Porém, ainda não existem estudos conclusivos acerca dos impactos negativos da cultura de eucalipto nos recursos hídricos. Apesar de estudos científicos e técnicos sobre as externalidades negativas da cultura do eucalipto não terem chegado a termo, o princípio 15 da Eco-92 impõe que:

De modo a proteger o meio ambiente, o princípio da precaução deve ser amplamente
observado pelos Estados, de acordo com suas capacidades. Quando houver ameaça
de danos sérios ou irreversíveis, a ausência de absoluta certeza científica não deve ser
utilizada como razão para postergar medidas eficazes e economicamente viáveis para
prevenir a degradação ambiental (CARVALHO, 2002, p. 139).

O princípio da precaução atua de modo a exigir a prudência do Estado, da sociedade civil e da iniciativa privada em relação a qualquer atividade humana, que, diante de incertezas científicas ou técnicas, possa gerar dúvida acerca de sua potencialidade para causar risco ao meio ambiente. Não há, pois, que se equivocar na identificação do princípio da precaução com o da prevenção, uma vez que este tem por diretriz prevenir impactos já conhecidos enquanto o anterior atua como alerta frente ao perigo ignorado (COSTA, 2005, p. 214).

Considerando a cultura do eucalipto como um tipo de floresta plantada em torno da qual há crescente demanda pela multiplicidade do uso comercial, industrial e energético dessa espécie vegetal, há que se esclarecer os mitos em relação à plantação das florestas de eucalipto. O primeiro deles é no sentido equivocado de que o eucalipto consome mais água para seu desenvolvimento do que outras plantas, chegando ao ponto de secar nascentes. No entanto, Thelma Shirlen Soares entende que a monocultura de eucalipto sofre certa "implicância devido a erros cometidos no início de sua plantação, quando a própria legislação permitia a substituição de matas nativas" (SOARES apud QUEIROZ, 2004, p. 39).

Quanto aos recursos hídricos, estudos desenvolvidos por Mora e Garcia (2000) demonstram que o consumo total de água por plantações de eucaliptos se equivale ao das árvores nativas, sendo até mesmo inferior ao das principais culturas agropecuárias. Por exemplo, com um litro de água o eucalyptus grandis é capaz de produzir 2,9 gramas de madeira, ao passo que uma espécie nativa do cerrado produz apenas 0,4 gramas com a mesma quantidade de água.

No que concerne, comparativamente, ao índice de remoção de nutrientes do solo em razão da espécie plantada, medido em $\mathrm{Kg} /$ hectare ao ano, veja-se a Tabela 3: 
Tabela 3 Consumo anual de nutrientes, em hectar, para cada espécie.

\begin{tabular}{|l|l|l|l|}
\hline \multicolumn{1}{|c|}{ Cultura } & Nitrogênio & Fósforo & Postássio \\
\hline Eucalipto & 13 & 4 & 44 \\
\hline Café & 93 & 4 & 127 \\
\hline Milho & 127 & 26 & 37 \\
\hline Cana-de-açúcar & 208 & 22 & 200 \\
\hline
\end{tabular}

Fonte: Mora e Garcia (2000, p. 79).

As pesquisas científicas ajudam a afastar mitos sobre os efeitos nocivos das florestas plantadas em relação às nascentes e rios. Para tanto, faz-se necessária a sinergia dos órgãos públicos e dos setores econômicos afetos à matéria, em parceria com os institutos de pesquisa.

A partir dessa perspectiva, os biólogos Cláudia Santana dos Santos e José Luis Caetano da Silva desenvolveram pesquisa sobre o impacto ambiental e social da plantação de florestas de eucalipto no extremo sul baiano. O resultado não foi favorável ao cultivo dessa espécie, pois demonstra vários aspectos prejudiciais (SANTOS; SILVA, 2004). Alguns deles serão aqui apontados.

Quanto ao solo da área do nordeste, mais especificamente do extremo sul baiano, afirmam os pesquisadores que a área apresenta relevo plano e ondulado, com clima quente e úmido, com temperaturas variando entre $22^{\circ}$ e $24^{\circ} \mathrm{C}$ e pluviosidade em torno de 1.500 a $1.750 \mathrm{~mm}$. Trata-se, portanto, de microrregião com pouca probabilidade de desertificação, mas que tem apresentado sérias modificações antrópicas, resultado das ações de madeireiros e carvoeiros sobre a cobertura vegetal, agravadas pela pecuária extensiva e monoculturas (SANTOS; SILVA, 2004).

Outro impacto nocivo sobre o solo baiano, especificamente no cultivo do eucalipto, deriva do uso intensivo de agrotóxicos. Esse fato preocupa mais em razão da proximidade dessas florestas plantadas com o entorno de unidades de conservação (SANTOS; SILVA, 2004).

No que concerne à disponibilização e ao uso dos recursos hídricos, a peculiaridade da região merece cuidados, uma vez que sua bacia hidrográfica se compõe de vários rios perenes, como o Jequinhonha, o Caraíva, o Cahy, o Jurucucu e o Santo Antônio (SANTOS; SILVA, 2004). Esses rios - e, por consequência, os córregos e riachos - correm sérios riscos de contaminação, porque já no plantio do eucalipto se inicia o uso dos recursos hídricos com irrigação e lavagem do maquinário de plantio e colheita (SANTOS; SILVA, 2004). 
Os pesquisadores descrevem os impactos que as fazendas de eucalipto causam na Mata Atlântica circundante, considerando que essas árvores têm crescimento acelerado, ou seja, concorrem com a cobertura vegetal natural do extremo sul baiano. Destacam, ainda, a proliferação das pragas típicas do eucalipto, como as saúvas cortadeiras e desfloradeiras que, após a colheita, migram para as florestas nativas remanescentes (SANTOS; SILVA, 2004).

Paralelamente, a cultura do eucalipto tem repercussões sociais, pois afetam as comunidades tradicionais da região, como alertam Gomes e Samapaio (2019, p. 96): "Há que ser lembrado o fato de os conhecimentos tradicionais serem elementos constitutivos e inseparáveis da cultura de cada comunidade tradicional". Desse modo, as comunidades que vivem da agricultura familiar de subsistência ficam comprometidas porque as terras agricultáveis, os recursos hídricos, a fauna e a flora sofrem com a interferência da plantação do eucalipto. Ademais, cerca de 30 mil hectares de terra que são reivindicados por estas comunidades se encontram atualmente cobertos pelos eucaliptos (SANTOS; SILVA, 2004). A mecanização do plantio é outro problema socioeconômico relevante. Como a colheita do eucalipto torna prescindível o aproveitamento da mão de obra local, a empregabilidade da atividade anunciada pelos empresários do setor florestal não se torna factível (SANTOS; SILVA, 2004).

De uma perspectiva mais focada nos recursos hídricos, Clarisse Barreto pesquisou o plantio de eucaliptos em alguns municípios rurais paulistas, entre os quais Caçapava, Santa Branca e Cunha, no Vale do Rio Paraíba. A autora explica que "Entre várias interpretações atribuídas à eucaliptocultura, aquela que diz respeito a seu efeito na redução de vazões de cursos d'água é uma crítica recorrente" (BARRETO, 2019, p. 10). Para verificar seu objeto de estudo, a autora pesquisou a correlação entre o nível pluviométrico das regiões e a quantidade, por hectare, de eucaliptocultura.

Barreto (2019) ilustra que, em 2014, os Municípios de Caçapava, Santa Branca e Cunha tinham, respectivamente, 2.515 ha, 4.000 ha e 1.245 ha de plantações de eucaliptos. Foram coletados pela pesquisadora, dados sobre a precipitação média anual de cada região e o potencial médio de evapotranspiração. A autora utilizou o método qualitativo de pesquisa, por meio de entrevistas semiestruturadas com perguntas relativas às modificações gerais no uso do solo e a diminuição de vazão de rios relativo à plantação de eucalipto (BARRETO, 2019). 
A autora conclui, em seu trabalho, que

A localização das propriedades em relação aos plantios apresentou-se como um fator que pode influenciar na percepcão desses plantios como um uso do solo que reduz as vazões dos cursos d'água, mas não foi determinante.

$[\ldots]$

Na pesquisa em tela, as representações dos plantios de eucalipto como um uso do solo que prejudica a disponbilidade hídrica foram construídas partindo de argumentos como a observação da redução de vazões de cursos d'água, a partir do momento em que esse uso do solo foi estabelecido em certos lugares, a área ocupada pelos plantios, seu estabelecimento próximo a cursos d'água, sua alta demanda por água, o rápido crescimento da árvore e suas raízes profundas. A experiência e a identidade de ex-trabalhadores em plantios surgiram como elementos legitimadores destes argumentos (BARRETO, 2019, p. 119).

Fazendo uma leitura crítica do trabalho de Barreto, nota-se que a pesquisa sobre o impacto da cultura do eucalipto sobre a vazão dos rios vem atrelada à conotação socioeconômica. Nos três municípios estudados, a coleta de dados por intermédio da entrevista semiestruturada detectou um problema com relação à empregabilidade da atividade, qual seja: "A ausência de geração de emprego pela empresa apresentou-se como uma forte crítica, principalmente em Santa Branca e em um bairro rural de Cunha" (BARRETO, 2019, p. 116). Logo, em termos aparentes, a diminuição da vazão do rio não seria considerada prejudicial pela população se houvesse empregos suficientes nessas cidades. A autora sintetiza suas observações sustentando que:

As impressões negativas geralmente apontam para a degradação ambiental e a baixa oferta de emprego. Notamos também que em Santa Branca, município com maior presença de plantios industriais organizados pela empresa, as falas dos entrevistados são mais complexas matizando e ponderando sobre as vantagens e prejuízos presentes na atividade. Assim compreendemos que as relações estabelecidas entre a atividade e as sociedades envolvidas foram representadas de variadas formas, revelando a enorme complexidade humana em questão. O Vale do Paraíba Paulista, região de ocupação antiga e de história longa de exploração capitalista dos recurso naturais, coloca desafios ao observador. Refletir sobre a disponibilidade hídrica e o desenvolvimento da eucaliptocultura industrial não pode destacar dados associais e econômicos como chave de compreensão da atividade. As múltiplas realidades reveladas pelas entrevistas demonstram que esta mensuração leva em consideração memórias individuais e compartilhadas, leituras do presente e expectativas de futuro que também se vinculam em quadros culturais, afetivos e sociais estabelecidos com o território (BARRETO, 2019, p. 117). 
Barreto conclui que, mesmo sendo evidente que a plantação de florestas de eucalipto diminui a vazão dos rios, essa não foi a maior preocupação das pessoas que vivem naqueles municípios. Todavia, elas sabem que aquela atividade causa impactos negativos sobre os recursos hídricos.

Embora seja relevante a pesquisa de Barreto (2019), há posições parcialmente destoantes, como a de Mora e Garcia (2000), que alegam que a cultura do eucalipto deve ser tecnicamente compreendida sob o aspecto agrícola-ambiental, à parte de qualquer análise relacionada à empregabilidade da atividade econômica. Nesse sentido, fazendo uma correlação entre a cultura do eucalipto e a disponibilidade e o uso dos recursos hídricos, Mora e Garcia (2000, p. 69) assentam que:

Culturalmente, tem-se uma ideia incorreta que o "eucalipto seca o solo". Inúmeros estudos já comprovaram que, no que diz respeito ao consumo de água e tolerância à seca ou a condições de déficit hídrico, existem respostas diferenciadas de acordo com cada cultura ou espécie plantada. No caso do eucalipto, algumas espécies da Austrália (E. regnans, E. marginata e E. Obliqua, por exemplo) realmente apresentam alto consumo de água, pois os estômatos permanecem abertos e, consequentemente, apresentam alta taxa de transpiração [...] Outras espécies já são mais eficientes no consumo de água do que inúmeras culturas agrícolas.

Portanto, há que se ter caulela quanto aos aspectos técnicos da produção de florestas plantadas de eucalipto e sua eventual pontencialidade para diminuir a vazão de rios ou secar recursos hídricos. Nesse cenário, Mora e Garcia informam que "A grande maioria das espécies de eucaliptos desenvolveu mecanismos fisiológicos de adaptação a condições de déficit hídrico (falta de água no solo), ou seja, mecanismos de restrição do consumo de água" (MORA; GARCIA, 2000, p. 71). E os autores garantem, ainda, por meio de pesquisa, que "Durante a fase de crescimento mais agudo, tanto o eucalipto como qualquer outro vegetal de rápido crescimento pode apresentar um balanço negativo entre a água infiltrada (chuva e irrigação) e a água retirada pelas raízes" (p. 71).

Ao tratarem da atividade de monocultura, Ching Liu, Kuchama e Krutovsky (2018, p. 5) alertam, de modo mais contundente, que:

Regarding the social impacts, the introduction of large-scale plantations often leads to the change in the ownership from local communities to large private companies, hence, resulting into a loss of traditional goods and cultures, customary rights, and livelihoods associated with forced resettlement and unequal distribution of resources [...]. Moreover, effects on the environment include the loss of soil productivity and fertility, disruption of hydrological cycles, risks associated with plantation forestry practices (e.g., introduction of exotic species), risks of promoting pests and diseases, $[\ldots] .^{4}$

4 Tradução livre: "Em relação aos impactos sociais, a introdução de plantações em grande escala geral- 
Todavia, Moledo et al. (2016) entendem que a cultura de eucalipto é uma atividade econômica relevante para o Brasil, e divergem da ideia de se atribuir ao eucalipto efeitos excessivamente nocivos ao meio ambiente. Os autores compreendem que "Quanto ao balanço hídrico em microbacias nas proximidades de florestas plantadas, o eucalipto sempre foi considerdo o grande vilão. Porém, essa afirmação é válida para a estação de verão, onde o consumo médio é de 15 1/dia, enquanto no inverno este valor cai para 4 1/dia".

Os referidos autores realizam trabalho técnico sobre os impactos do plantio da cultura de eucalipto e apresentam plano de manejo bem estruturado para mitigar todos os seus aspectos negativos. As consequências, conforme já identificadas em outros trabalhos, repercutem geralmente nos recursos hídricos, na fauna, na flora e em aspectos socieconômicos. Entretanto, os autores atestam que com emprego de estudos complexos e manejo adequado, todos os problemas listados podem ser resolvidos ou mitigados, pois "o manejo florestal ou manejo autossustentado é aplicação de métodos empresariais e de boas práticas suportadas por conhecimento técnico. Entre os princípios tem-se a silvicultura, que é uma parte determinante dos planos de manejo" (MOLEDO et al., 2016, p. 514).

Moledo et al. (2016) comprovam em seu trabalho, que o plano de manejo florestal tem função primordial na operação e gestão de áreas de silvicultura. Entendem que "os planos de manejo principalmente no nível operacional devem ser especificamente desenvolvidos com base nas características geoambientais das áreas a serem exploradas possibilitando o estabelecimento de práticas operacionais adequadas para a realizacão de ações sustentáveis" (p. 529).

Como se pode constatar, quase todos os autores concordam que existem vários impactos da cultura do eucalipto no meio ambiente, e particularmente nos recursos hídricos. Entretanto, a postura de Mora e Garcia, mesmo sendo um trabalho mais antigo, do ano 2000, demonstram um equilíbrio de pensamento, principalmente quando afirmam:

Do ponto de vista físico, vários plantios ocuparam terras em locais não recomendados, como áreas consideradas aptas para culturas agrícolas, encostas íngremes, margens de rios e outras. Também ocorreram, em certas regiões, mudanças na paisagem

mente leva à transferência de propriedade das comunidades locais para as grandes empresas privadas, resultando em perda de bens e culturas tradicionais, direitos consuetudinários e meios de subsistência associados ao reassentamento forçado e distribuição desigual de recursos (BALTODANO, 2000; COLCHESTER, 2006). Além disso, os efeitos no meio ambiente incluem perda de produtividade e fertilidade do solo, interrupção dos ciclos hidrológicos, riscos associados a práticas florestais de plantio (por exemplo, introdução de espécies exóticas), perigo de novas pragas e doenças, [...]." 
mesmo em áreas já degradadas por atividades extrativas. Em função dos sistemas de planejamento operacional adotados, houve interferência dos plantios nos processos de conservação do solo (erosão) e qualidade da água. Tendo em consideração os aspectos biológicos, os primeiros projetos não consideraram os planos de manejo para garantia da biodiversidade dos sistemas aquáticos e terrestres, com consequências até os dias atuais. O uso de defensivos agrícolas e fertilizantes foi realizado com conhecimentos limitados sobre suas interferências junto aos seres humanos e ambiente. Também o uso de fogo controlado como método de limpeza de área pré-plantio e dos sistemas de prevenção e combate aos incêndios florestais foi intensamente questionado. Os desmatamentos e as queimadas inflamaram os questionamentos sobre o "efeito Estufa” (MORA; GARCIA, 2000, p. 78).

Percebe-se que as práticas do plantio do eucalipto, nos ciclos citados anteriormente, foram realizadas sem estudos adequados e sem considerar as complexidades de ser o eucalipto uma planta pertencente a outro bioma. Logo, o plantio feito sem a observância de certos cuidados causou impactos ambientais e socioeconômicos com consequências atuais. A leitura de vários artigos nacionais e estrangeiros demonstra que, em outros países, também existem alguns mitos sobre a monocultura de eucalipto.

Todavia, os textos utilizados neste trabalho deixam fortes indícios quanto aos benefícios das florestas plantadas, sendo o principal deles a possibilidade de reversão do desflorestamento das matas nativas, quando devidamente cultivadas. Ademais, as florestas plantadas auxiliam no controle da erosão desde que tomadas medidas adequadas de manejo de solo, ou seja, atuam na fixação do solo e no escoamento da chuva, regulando o ciclo de água nas microbacias onde estão inseridas as florestas (MORA, GARCIA, 2000). Paralelamente, o valor comercial e industrial da cultural de eucalipto se abre a diversos segmentos socioeconômicos relevantes para o desenvolvimento sustentável brasileiro.

Conforme informações colhidas na elaboração deste trabalho, e em razão de sua extensão e sua profundidade, não é conclusivo o posicionamento favorável ou contrário à produção de florestas plantadas de eucalipto no Brasil. Porém, a questão é mais afeita à elaboração, implementação, monitoramento, avaliação e atualização de políticas públicas (CUSTÓDIO; OLIVEIRA, 2015) para administrar os problemas que surgem com a crescente cultura de eucalipto.

Em contrapartida, restou evidente que as florestas plantadas têm função relevante como alternativa de desenvolvimento socioeconômico sustentável por retirarem das florestas naturais a demanda crescente por madeira nos mais diversos segmentos industriais e comerciais. Nesse 
cenário, faz-se necessário um arcabouso legal próprio e a implementação de medidas administrativas adequadas de fomento do setor, em parceria com a sociedade civil e a iniciativa privada, de modo a compatibilizá-lo com a necessária proteção ambiental, especificamente com a conservação, a disponibilização e a utilização de recursos hídricos.

\section{CONSIDERAÇÕES FINAIS}

Partindo do tema-problema proposto, analisado no contexto do marco téorico, e de modo a responder às hipóteses apresentadas, pode-se concluir que há vigoroso debate científico quanto ao grau de nocividade ou não da cultura de eucalipto. Como citado no texto, existem algumas espécies que podem causar grande impacto e outras que, em razão dos cuidados específicos, como na escolha da região, tornam possível que o plantio seja benéfico. Assim, de início, seria recomendada a observância do princípio da precaução na atividade de plantio do eucalipto, de modo que nessa cultura sejam selecionadas as espécies de menor impacto.

A longa experiência do plantio do eucalipto em território nacional e os conhecimentos que dela podem surgir permitem que se considere alguns aspectos positivos dessa cultura. $\mathrm{O}$ primeiro deles diz respeito aos avanços genéticos pelos quais têm passado o aperfeiçoamento da espécie, de maneira a causar menor impacto ambiental e de gerar maior proveito econômico para os fins a que se destina a produção. O segundo fator está na multiplicidade de seu uso comercial, industrial e energético e em sua potencialidade para atender à crescente demanda mundial por madeira. Um terceiro aspecto muito relevante é o da preservação das florestas nativas, que passam a ser objeto de menor procura e especulação, como consequência da substituição do suprimento desta demanda pelas florestas plantadas, que tem como consequência a licitude e o controle do corte de madeiras neste segmento. Uma quarta particularidade está no fato de que estudos comprovam que políticas públicas adequadas de plantio do eucalipto podem diminuir substancialmente os efeitos nocivos dessa cultura. Portanto, o setor de florestas plantadas, se bem organizado e monitorado, pode se converter em importante meio de desenvolvimento sustentável ao mesmo tempo em que supre as legítimas demandas por mandeira e por fontes energéticas, especialmente a da biomassa.

Em conclusão, o artigo propõe que, com relação à cultura do eucalipto 
como modalidade de floresta plantada com finalidades comerciais, industriais e energéticas, o princípio ambiental de aplicação mais adequada é o da prevenção, em vez do princípio da precaução. O trabalho recomenda a observância do princípio da prevenção em razão da boa experiência e dos conhecimentos já adquiridos com a longa cultura do eucalipto no Brasil. Ademais, o princípio da precaução não pode ser aplicado de modo inflexível, pois seria impeditivo ao desenvolvimento do setor de florestas plantadas, que cumprem funções socioeconômicas e até ambientais relevantes, conforme relatado no parágrafo anterior.

As pesquisas nesse segmento devem continuar para que o plantio do eucalipto seja feito com a necessária reserva da proteção ambiental. A hipótese apresentada na introdução confirmou-se parcialmente, ou seja, que a cultura do eucalipto não deve ser substituída por outra, mas sujeita a elaboração, implementação, monitoramento, avaliação e atualização de políticas públicas específicas e adequadas para administrar os problemas ambientais que surgem a partir desta, em observância ao princípio da prevenção.

Logo, ainda que não sejam totalmente conclusivos, os estudos técnicos e científicos dos impactos ambientais do plantio do eucalipto, os conhecimentos já adquiridos pela longa tradição e experimentação dessa cultura em território brasileiro, somados às boas perspectivas do manejo bem-estruturado já aplicadas neste segmento, recomendam a continuidade da atividade econômica, sob o contexto do princípio da prevenção.

\section{REFERÊNCIAS}

BARRETO, C. A. Eucalipto, água e sociedade: a construção de representantes no Vale do Paraíba, SP. Tese (Doutorado em Ecologia Aplicada) - Centro de Energia Nuclear da Agricultura, Escola Superior de Agricultura "Luiz de Queiroz", Universidade de São Paulo, São Paulo, 2019.

BORGES, M. G.; LEITE, M. E.; LEITE, M. R. Mapeamento do eucalipto no estado de Minas Gerais utilizando o Sensor Modis. Espaço Aberto, Rio de Janeiro, v. 8, n. 1, p. 53-70, 2018. Disponível em: https://revistas.ufrj. br/index.php/EspacoAberto/article/download/14364/11776. Acesso em: 20 nov. 2019.

CARVALHO, C. M., SILVA, W. Essências florestais no Brasil. Revista 
Silvicultura, São Paulo, n. 43, p. 42-43, 1992.

CARVALHO, R. M. M. A. et al. Terceirização: considerações e reflexões. In: CONGRESSO BRASILEIRO DE DESENVOLVIMENTO SUSTENTÁVEL PARA A INDÚSTRIA DE BASE FLORESTAL E DE GERAÇÃO DE ENERGIA, 2, 2004, Belo Horizonte. Revista Madeira 2004. Belo Horizonte: AMS, 2004. v. 2. p. 47-48.

CHING LIU, C. L.; KUCHMA; O.; KRUTOVSKY, K. V. Mixed-species versus monocultures in plantation forestry: Development, benefits, ecosystem services and perspectives for the future. Global Ecology Conservation, v. 15, n. 419, p. 01-15, jul. 2018.

COSTA, B. S. Plantações de florestas ou reflorestamento? Revista Brasileira de Direito Ambiental, São Paulo, ano 1, v. 2, p. 213-226, abr./ jun. 2005.

CUSTÓDIO, M. M.; OLIVEIRA, M. L. Eco-efficiency in bidding processes to purchase everyday supplies for the brazilian federal administration. Veredas do Direito, Belo Horizonte, v. 12, n. 24, p. 33-61, jul./dez., 2015. Disponível em: http:/www.domhelder.edu.br/revista/index.php/veredas/ article/view/647/454. Acesso em: 20 nov. 2019.

EMBRAPA - EMPRESA BRASILEIRA DE PESQUISA AGROPECUÁRIA. O eucalipto. Disponível em: https://www.embrapa.br/ florestas/transferencia-de-tecnologia/eucalipto Acesso em: 20 nov. 2019.

FAO - FOOD AND AGRICULTURE ORGANIZATION OF THE UNITED NATIONS. Forest resources assessment working paper: terms and definitions, 2015a. Disponível em: http://www.fao.org/3/ap862e/ ap862e00.pdf. Acesso em: 20 nov. 2019.

FAO-FOOD ANDAGRICULTURE ORGANIZATION OF THE UNITED NATIONS. Global Forest resource assessment, 2015b. Disponível em: http://www.fao.org/3/a-i4808e.pdf. Acesso em: 20 nov. 2019.

GOMES, M. F.; SAMPAIO, J. A. L. Biopirataria e conhecimentos tradicionais: as faces do biocolonialismo e sua regulação. Veredas do Direito, Belo Horizonte, v. 16, n. 34, p. 91-121, jan./abr. 2019. Disponível em: http:/www.domhelder.edu.br/revista/index.php/veredas/article/ view/1274/24726. Acesso em: 20 nov. 2019. 
IBÁ - INDÚSTRIA BRASILEIRA DE ÁRVORES. Relatório 2017. Disponível em: https://iba.org/images/shared/Biblioteca/IBA_ RelatorioAnual2017.pdf. Acesso em: 20 nov. 2019.

MOLEDO, J. C. et al. Impactos ambientais relativos à silvicultura de eucalipto: uma análise comparativa do desenvolvimento e aplicação no plano de manejo florestal. Revista Geociências, São Paulo, v. 35, n. 4, p. 512-530, 2016.

MORA, A. L.; GARCIA, C. H. A cultura do eucalipto no Brasil. São Paulo: Sociedade Brasileira de Silvicultura, 2000. Disponível em: http:// atividaderural.com.br/artigos/50ec5305728a6.pdf. Acesso: 1 set. 2019.

QUEIROZ, C. A. S. Influência de regulador de fluxo na velocidade operacional de pulverizadores usados em florestamentos. In: CONGRESSO BRASILEIRO DE DESENVOLVIMENTO SUSTENTÁVEL PARA A INDÚSTRIA DE BASE FLORESTAL E DE GERAÇÃO DE ENERGIA, 2, 2004, Belo Horizonte. Revista Madeira 2004. Belo Horizonte: AMS, 2004. v. 2. p. 47-48.

SANTAROSA, E.; PENTEADO JÚNIOR, J. F.; GOULART, I. C. G. R. (ed.). Transferência de tecnologia florestal: cultivo de eucalipto em propriedades rurais: diversificação da produção e renda. Brasília, DF: Embrapa, 2014. Disponível em: https://ainfo.cnptia.embrapa.br/digital/ bitstream/item/121607/1/Apostila-Serie-TT-Eucalipto.pdf. Acesso em: 20 nov. 2019.

SANTOS, C. S.; SILVA, J. L. C. Os impactos do plantio de eucalipto e da produção de celulose em comunidades tradicionais do extremo sul baiano. p. 4, 2004. Disponível em: http//www.anppas.org.br/encontro/segundo/ Papers/GT17/gt17_Jose_Caetano.PDF. Acesso em: 6 set. 2019.

SNIF - SISTEMA NACIONAL DE INFORMAÇÕES FLORESTAIS. Boletim SNIF 2018 ed.1. 2018. Disponível em: http://www.florestal.gov. br/publicacoes/1645-boletim-snif-2018-ed-1. Acesso em: 20 nov. 2019.

Artigo recebido em: 02/10/2019. Artigo aceito em: 19/11/2019. 


\section{Como citar este artigo (ABNT):}

COSTA, B. S.; OLIVEIRA, M. L. Florestas plantadas de eucalipto no Brasil: uma cultura nociva aos recursos hídricos? Veredas do Direito, Belo Horizonte, v. 16, n. 36, p. 123-141, set/dez. 2019. Disponível em: http:// www.domhelder.edu.br/revista/index.php/veredas/article/view/1671. Acesso em: dia mês. ano. 